\title{
Growth curves of myopia-related parameters to clinically monitor the refractive development in Chinese schoolchildren
}

\author{
Pablo Sanz Diez ${ }^{1,5}$ (1) $\cdot$ Li-Hua Yang ${ }^{2} \cdot$ Mei-Xia Lu ${ }^{3,4} \cdot$ Siegfried Wahl ${ }^{1,5} \cdot$ Arne Ohlendorf ${ }^{1,5}$
}

Received: 31 October 2018 / Revised: 26 February 2019 / Accepted: 3 March 2019 / Published online: 23 March 2019

(C) The Author(s) 2019

\begin{abstract}
Purpose To produce a clinical model for the prediction of myopia development based on the creation of percentile curves of axial length in school-aged children from Wuhan in central China.

Methods Data of 12,554 children (6054 girls and 6500 boys) were collected and analyzed for the generation of the axial length growth curves. A second data set with 226 children and three yearly successive measurements was used to verify the predictive power of the axial length growth percentile curves. Percentile curves were calculated for both gender groups and four age groups $(6,9,12$, and 15 years). The second data set was used to verify the efficacy of identifying the refractive error of the children using the axial length curves, based on their spherical refractive error from the third visit.

Results From 6 to 15 years of age, all percentiles showed a growth trend in axial length, except for the percentiles below the first quartile, which appear to stabilize after the age of $12(-0.10 ; 95 \% \mathrm{CI},-0.36-0.16 ; P=0.23$ for girls; $-0.16 ; 95 \% \mathrm{CI},-0.70-$ $0.39 ; P=0.34$ for boys); however, the growth continued for the remaining $75 \%$ of cases. The second data set showed that the likelihood of suffering high myopia (spherical refractive error $\leq-5.00 \mathrm{D}$ ) during adolescent years increased when axial length values were above the first quartile, for both genders.

Conclusions The data from the current study provide a tool to observe the annual growth rates of axial length and can be considered as an approach to predict the refractive development at school ages.
\end{abstract}

Keywords Myopia $\cdot$ Axial length $\cdot$ Refraction $\cdot$ Children $\cdot$ Growth charts $\cdot$ Percentiles

\section{Introduction}

Understanding the refractive development of the visual system from birth is a key point in vision research, especially with

Pablo Sanz Diez

pablo.sanz-diez@student.uni-tuebingen.de

1 Carl Zeiss Vision International GmbH, Technology and Innovation, Turnstraße 27, 73430 Aalen, Germany

2 Wuhan Center for Adolescent Poor Vision Prevention and Control, Wuhan 430015, China

3 Wuhan Commission of Experts for the Prevention and Control of Adolescent Poor Vision, Wuhan 430015, China

4 Department of Epidemiology and Statistics, School of Public Health, Tongji Medical College, Huazhong University of Science and Technology, Wuhan 430030, China

5 Institute for Ophthalmic Research, Eberhard Karls University Tuebingen, Elfriede-Aulhorn-Straße 7, 72076 Tuebingen, Germany regards to growing interest in understanding the origin and development of refractive errors, such as hyperopia and myopia. A typical refractive development of the visual system is characterized by a hyperopic refractive state (in terms of the spherical equivalent) at birth, which decreases as age increases [1]. During the first 2 years of life, the most significant changes occur for the axial length of the eye and its corneal curvature, which determine the changes in the refractive state of the eye during the early years of childhood $[2,3]$. At 6 years of age, the refractive of children in most populations is known to be leptokurtic, with a positively skewed distribution [4]. With the increasing prevalence of myopia in East Asia, researchers describe a distribution with reduced leptokurtosis and a negative skew in that population [4]. As myopia and especially high myopia $(<-5 \mathrm{D})$ is known to have consequences for the health of the eye, as for example reviewed by Ikuno [5], myopia research has become more into the public focus. In order to decode the increasing prevalence of myopia, researchers have experimentally tried to explore the different theories about the onset and progression of myopia in animal studies 
[6]. Epidemiological research has been carried out in order to better determine the risk factors that lead to myopic refractive errors. Among the parental history of refractive errors, the ethnicity, or the level of education, many more risk factors have been described in the literature [7-12]. While different factors have been identified that influence the onset and development of progressive myopia, certain forms of stable myopia that are notable after birth have been described in the literature $[13,14]$. Additionally, researchers have tried to develop models to predict the onset as well as the progression of myopia, based on different parameters, such as uncorrected visual acuity, axial length, corneal curvature, accommodative lag, $\mathrm{AC} / \mathrm{C}$ ratio, and crystalline lens power [15-19].

To test and compare the children's growth and development (from birth to juvenileness), pediatricians use percentile charts for variables such as weight, height, as well as body mass [20], and this statistical measure allows to assess and compare the growth of a variable in relation to a standard range. As far as the development of the visual system is concerned, these types of growth reference charts have only recently started to be used in ophthalmology [21,22].

The purpose of this study was to produce a clinical estimation model for the prediction of myopia development, based on the creation of percentile curves of axial length for a large cohort of Chinese students in primary and secondary schools in the city of Wuhan. These percentiles will provide ranges of axial length values in order to understand the growth and the development of the visual system in the children and adolescent of Chinese populations.

\section{Material and methods}

\section{Subjects}

Data of 12,780 children were collected by the Wuhan Center for Adolescent Poor Vision Prevention and Control. The total data set was divided into two sets, one consisting of 12,554 children with individual data corresponding to a single visit and another set consisting of 226 children with longitudinal data. The first data set $(12,554$ children) was used for the development of the growth curves. This study cohort consisted of children from 5 to 16 years (mean spherical refractive error: $-0.91 \pm 1.84 \mathrm{D}$ ) divided into two groups based on gender. The two groups consisted of 6054 girls (mean age $9.99 \pm 2.47$ years, mean SR: $-0.93 \pm 1.85 \mathrm{D})$ and 6500 boys (mean age $9.90 \pm 2.48$ years, mean spherical refractive error: $-0.88 \pm 1.83 \mathrm{D})$.

To validate the efficacy of the developed axial length growth percentile curves, the second data set (226 children) with three successive measurements of the same variables (Table 1) was used (average time between 1st and 3rd visit:
$2.67 \pm 2.96$ years and $2.57 \pm 2.77$ years for girls and boys, respectively).

\section{Data acquisition}

The data set contained the age and gender of each subject as well as the following ocular parameters from both eyes: spherical refractive error (SR), axial length (AL), and corneal radius (CR).

The measurement of the ocular parameters was accomplished using a non-invasive and non-contact biometer, Lenstar LS 900 SN 1914, V.1.1.0 (HaagStreit AG, Koeniz, Switzerland) [23]. AL was measured as the distance from the anterior corneal surface to the retinal pigment epithelium (RPE). CR was identified as the mean of the flattest and steepest radii. Moreover, the $\mathrm{AL} / \mathrm{CR}$ ratio was calculated in order to obtain more information regarding the association between both variables.

The autorefractor Topcon CV-3000 Compu Vision (Topcon, Tokyo, Japan) was used to measure the spherical refractive error. Measurements of the spherical refractive error were obtained under cycloplegia (4 drops of $0.5 \%$ Cyclopentolate, instilled at 5-min intervals), and three consecutive measurements of the spherical refraction were obtained after the full cycloplegic effect emerged ( $25 \mathrm{~min}$ after the last drop). The refractive state of the subjects was defined as myopia (SR $\leq-0.50 \mathrm{D})$, emmetropia $(-0.50<\mathrm{SR} \leq+0.50 \mathrm{D})$, hyperopia (SR $>+0.50 \mathrm{D})$, and high myopia $(\mathrm{SR} \leq-5.00 \mathrm{D})$. Only the data from the right eye was used for the final analysis.

\section{Statistical analysis}

Statistical analysis was performed with the SPSS statistical software package, version 22.0 for Windows (SPSS, Chicago, Illinois, USA). Statistical analysis was accomplished in order to compare differences among gender and age groups. Analysis of variance (ANOVA) or Kruskal-Wallis tests were used depending on the distribution of the data. The least significant difference (LSD) test was used for the post hoc comparative analysis. Differences were considered statistically significant when the associated $p$ value was less than 0.05 . The 2nd, 5th, 10th, 25th, 50th, 75th, 90th, 95th, and 98th percentile curves were computed for $\mathrm{AL}$ taking into account both gender and different age groups. Receiver operating characteristic (ROC) analysis was carried out in order to obtain the diagnostic performance of the $\mathrm{AL}$ growth percentile curves, where an area of 1.0 represents an ideal test and an area of 0.5 denotes a worthless test. 
Table 1 Mean values of AL, CR, AL/CR ratio, and SR in the group of children for the validation analysis, according to gender

\begin{tabular}{|c|c|c|c|c|c|c|}
\hline & \multicolumn{3}{|l|}{ Female } & \multicolumn{3}{|l|}{ Male } \\
\hline & 1 st visit & 2nd visit & 3rd visit & 1st visit & 2nd visit & 3rd visit \\
\hline Sample size & 92 & 91 & 92 & 134 & 134 & 134 \\
\hline Mean age $\pm \mathrm{SD}$ & $8.91 \pm 2.99$ & $10.41 \pm 2.01$ & $11.59 \pm 2.18$ & $8.95 \pm 1.88$ & $10.43 \pm 1.93$ & $11.51 \pm 2.04$ \\
\hline $\mathrm{AL}$ mean $\pm \mathrm{SD}(\mathrm{mm})$ & $23.42 \pm 1.01$ & $24.20 \pm 1.01$ & $24.63 \pm 1.03$ & $23.88 \pm 0.99$ & $24.63 \pm 1.11$ & $25.07 \pm 1.13$ \\
\hline $\mathrm{CR}$ mean $\pm \mathrm{SD}(\mathrm{mm})$ & $7.77 \pm 0.26$ & $7.78 \pm 0.26$ & $7.77 \pm 0.26$ & $7.81 \pm 0.25$ & $7.80 \pm 0.25$ & $7.80 \pm 0.24$ \\
\hline $\mathrm{AL} / \mathrm{CR}$ mean $\pm \mathrm{SD}(\mathrm{mm})$ & $3.01 \pm 0.12$ & $3.11 \pm 0.12$ & $3.17 \pm 0.13$ & $3.06 \pm 0.13$ & $3.16 \pm 0.14$ & $3.21 \pm 0.15$ \\
\hline $\mathrm{SR}$ mean $\pm \mathrm{SD}(\mathrm{D})$ & $-0.72 \pm 1.68$ & $-1.87 \pm 1.80$ & $-2.77 \pm 1.86$ & $-0.96 \pm 1.77$ & $-2.02 \pm 2.04$ & $-2.86 \pm 2.09$ \\
\hline Prevalence hyperopia & $15.22 \%$ & $4.54 \%$ & $4.35 \%$ & $14.93 \%$ & $7.63 \%$ & $2.99 \%$ \\
\hline Prevalence emmetropia & $15.22 \%$ & $10.23 \%$ & $4.35 \%$ & $15.67 \%$ & $11.45 \%$ & $5.97 \%$ \\
\hline Prevalence myopia & $69.56 \%$ & $84.09 \%$ & $83.69 \%$ & $67.91 \%$ & $74.81 \%$ & $76.87 \%$ \\
\hline Prevalence high myopia & $0.00 \%$ & $1.14 \%$ & $7.61 \%$ & $1.49 \%$ & $6.11 \%$ & $14.18 \%$ \\
\hline
\end{tabular}

$A L$ axial length, $C R$ corneal radius, $A L / C R$ axial length/corneal radius, $S R$ spherical refractive error

\section{Results}

\section{Prevalence of refractive errors}

The prevalence of refractive errors, separated for the two genders, is shown in Table 2 and Table 3. It can be observed that at the age of 5 years, the prevalence of hyperopia was above $70.00 \%$ in both groups $(80.67 \%$ for girls and $70.53 \%$ for boys), while the prevalence of myopia was lower than $10.00 \%$ (4.00\% for girls and $6.32 \%$ for boys), and besides $13.30 \%$ of the girls and $23.16 \%$ of the boys were classified as emmetropic. With increasing age, the prevalence of hyperopia and myopia behaved in opposite ways. Between 7 and 8 years of age, myopia became the refractive state with the highest prevalence $(56.56 \%$ girls and $54.56 \%$ boys), compared to prevalence of hyperopia $(20.55 \%$ girls and $21.72 \%$ boys). In children aged 11 years, the prevalence of myopia exceeded $80.00 \%$ in both groups, while the prevalence additionally increased up to $87.93 \%$ for girls and $93.44 \%$ for boys, at the age of 16 years. Summarized, the SR was an age-dependent variable in both females and males (ANOVA, LSD post hoc, $F=234.216 P<0.001, F=228.614$ $P<0.001$, respectively), but not gender-dependent $(P>0.05$ in each age group, Table 2 and Table 3 ).

\section{Age-related changes in ocular variables}

The mean values of the variables $\mathrm{AL}, \mathrm{CR}, \mathrm{AL} / \mathrm{CR}$ ratio, and SR depending on the gender and age (from 5 to 16 years of age) are also shown in Table 2 and Table 3. Mean AL was

Table 2 Mean values of AL, CR, AL/CR ratio, and SR depending on age in the female group

\begin{tabular}{|c|c|c|c|c|c|c|c|c|}
\hline \multirow[t]{2}{*}{ Age } & \multicolumn{8}{|l|}{ Female } \\
\hline & $\begin{array}{l}\text { Sample } \\
\text { size }\end{array}$ & $\begin{array}{l}\text { AL mean } \pm \mathrm{SD} \\
(\mathrm{mm})\end{array}$ & $\begin{array}{l}\mathrm{CR} \text { mean } \pm \mathrm{SD} \\
(\mathrm{mm})\end{array}$ & $\begin{array}{l}\mathrm{AL} / \mathrm{CR} \text { mean } \pm \mathrm{SD} \\
(\mathrm{mm})\end{array}$ & $\begin{array}{l}\mathrm{SR} \text { mean } \pm \mathrm{SD} \\
\text { (D) }\end{array}$ & $\begin{array}{l}\text { Prevalence } \\
\text { hyperopia }\end{array}$ & $\begin{array}{l}\text { Prevalence } \\
\text { emmetropia }\end{array}$ & $\begin{array}{l}\text { Prevalence } \\
\text { myopia }\end{array}$ \\
\hline 5 & 75 & $22.17 \pm 0.81$ & $7.80 \pm 0.25$ & $2.84 \pm 0.08$ & $+1.53 \pm 1.52$ & $82.67 \%$ & $13.33 \%$ & $4.00 \%$ \\
\hline 6 & 474 & $22.56 \pm 0.78$ & $7.75 \pm 0.25$ & $2.91 \pm 0.09$ & $+0.85 \pm 1.27$ & $60.97 \%$ & $26.37 \%$ & $12.63 \%$ \\
\hline 7 & 1062 & $22.84 \pm 0.88$ & $7.73 \pm 0.24$ & $2.95 \pm 0.10$ & $+0.29 \pm 1.38$ & $43.88 \%$ & $29.76 \%$ & $26.37 \%$ \\
\hline 8 & 686 & $23.40 \pm 0.93$ & $7.74 \pm 0.25$ & $3.02 \pm 0.10$ & $-0.54 \pm 1.49$ & $20.55 \%$ & $22.89 \%$ & $56.56 \%$ \\
\hline 9 & 917 & $23.73 \pm 0.89$ & $7.77 \pm 0.25$ & $3.06 \pm 0.10$ & $-1.03 \pm 1.45$ & $9.92 \%$ & $20.50 \%$ & $69.57 \%$ \\
\hline 10 & 839 & $23.92 \pm 0.90$ & $7.75 \pm 0.24$ & $3.09 \pm 0.11$ & $-1.37 \pm 1.56$ & $7.51 \%$ & $14.66 \%$ & $77.83 \%$ \\
\hline 11 & 561 & $24.15 \pm 0.93$ & $7.77 \pm 0.24$ & $3.11 \pm 0.11$ & $-1.75 \pm 1.52$ & $4.46 \%$ & $9.27 \%$ & $86.27 \%$ \\
\hline 12 & 590 & $24.16 \pm 0.96$ & $7.74 \pm 0.26$ & $3.12 \pm 0.12$ & $-1.88 \pm 1.74$ & $3.39 \%$ & $9.83 \%$ & $86.78 \%$ \\
\hline 13 & 431 & $24.29 \pm 1.03$ & $7.77 \pm 0.27$ & $3.13 \pm 0.12$ & $-2.09 \pm 1.71$ & $2.55 \%$ & $10.21 \%$ & $87.24 \%$ \\
\hline 14 & 251 & $24.44 \pm 1.03$ & $7.78 \pm 0.25$ & $3.14 \pm 0.13$ & $-2.26 \pm 1.96$ & $3.98 \%$ & $6.77 \%$ & $89.24 \%$ \\
\hline 15 & 110 & $24.50 \pm 1.15$ & $7.77 \pm 0.28$ & $3.16 \pm 0.15$ & $-2.51 \pm 2.20$ & $1.82 \%$ & $10.00 \%$ & $88.18 \%$ \\
\hline 16 & 58 & $24.73 \pm 1.13$ & $7.86 \pm 0.26$ & $3.15 \pm 0.14$ & $-2.72 \pm 2.15$ & $3.45 \%$ & $8.62 \%$ & $87.93 \%$ \\
\hline
\end{tabular}

$A L$ axial length, $C R$ corneal radius, $A L / C R$ axial length/corneal radius, $S R$ spherical refractive error 
Table 3 Mean values of AL, CR, AL/CR ratio, and SR depending on age in the male group

\begin{tabular}{|c|c|c|c|c|c|c|c|c|}
\hline \multirow[t]{2}{*}{ Age } & \multicolumn{8}{|l|}{ Male } \\
\hline & $\begin{array}{l}\text { Sample } \\
\text { size }\end{array}$ & $\begin{array}{l}\mathrm{AL} \text { mean } \pm \mathrm{SD} \\
(\mathrm{mm})\end{array}$ & $\begin{array}{l}\mathrm{CR} \text { mean } \pm \mathrm{SD} \\
(\mathrm{mm})\end{array}$ & $\begin{array}{l}\mathrm{AL} / \mathrm{CR} \text { mean } \pm \mathrm{SD} \\
(\mathrm{mm})\end{array}$ & $\begin{array}{l}\mathrm{SR} \text { mean } \pm \mathrm{SD} \\
\text { (D) }\end{array}$ & $\begin{array}{l}\text { Prevalence } \\
\text { hyperopia }\end{array}$ & $\begin{array}{l}\text { Prevalence } \\
\text { emmetropia }\end{array}$ & $\begin{array}{l}\text { Prevalence } \\
\text { myopia }\end{array}$ \\
\hline 5 & 95 & $22.71 \pm 0.85$ & $7.85 \pm 0.26$ & $2.89 \pm 0.10$ & $+1.18 \pm 1.52$ & $70.53 \%$ & $23.16 \%$ & $6.32 \%$ \\
\hline 6 & 500 & $23.03 \pm 0.82$ & $7.84 \pm 0.24$ & $2.94 \pm 0.09$ & $+0.71 \pm 1.36$ & $58.80 \%$ & $24.20 \%$ & $17.20 \%$ \\
\hline 7 & 1228 & $23.31 \pm 0.87$ & $7.85 \pm 0.25$ & $2.97 \pm 0.10$ & $+0.27 \pm 1.33$ & $41.86 \%$ & $31.19 \%$ & $26.95 \%$ \\
\hline 8 & 801 & $23.88 \pm 0.96$ & $7.86 \pm 0.26$ & $3.04 \pm 0.11$ & $-0.52 \pm 1.51$ & $21.72 \%$ & $23.72 \%$ & $54.56 \%$ \\
\hline 9 & 912 & $24.26 \pm 0.92$ & $7.88 \pm 0.25$ & $3.08 \pm 0.10$ & $-1.02 \pm 1.44$ & $10.53 \%$ & $18.09 \%$ & $71.38 \%$ \\
\hline 10 & 899 & $24.44 \pm 0.94$ & $7.88 \pm 0.25$ & $3.10 \pm 0.12$ & $-1.29 \pm 1.60$ & $8.68 \%$ & $16.57 \%$ & $74.75 \%$ \\
\hline 11 & 580 & $24.69 \pm 0.99$ & $7.89 \pm 0.26$ & $3.13 \pm 0.11$ & $-1.71 \pm 1.68$ & $4.14 \%$ & $11.90 \%$ & $83.97 \%$ \\
\hline 12 & 555 & $24.82 \pm 0.93$ & $7.88 \pm 0.25$ & $3.15 \pm 0.12$ & $-1.92 \pm 1.67$ & $4.50 \%$ & $8.83 \%$ & $86.67 \%$ \\
\hline 13 & 515 & $24.81 \pm 0.97$ & $7.88 \pm 0.26$ & $3.15 \pm 0.12$ & $-1.91 \pm 1.75$ & $5.83 \%$ & $11.07 \%$ & $83.11 \%$ \\
\hline 14 & 227 & $24.96 \pm 1.02$ & $7.90 \pm 0.24$ & $3.16 \pm 0.12$ & $-2.17 \pm 1.84$ & $2.20 \%$ & $10.57 \%$ & $87.22 \%$ \\
\hline 15 & 127 & $25.15 \pm 1.28$ & $7.88 \pm 0.27$ & $3.19 \pm 0.15$ & $-2.63 \pm 2.20$ & $2.36 \%$ & $4.72 \%$ & $92.19 \%$ \\
\hline 16 & 61 & $25.19 \pm 1.06$ & $7.88 \pm 0.25$ & $3.19 \pm 0.13$ & $-2.68 \pm 1.90$ & $3.28 \%$ & $3.28 \%$ & $93.44 \%$ \\
\hline
\end{tabular}

$A L$ axial length, $C R$ corneal radius, $A L / C R$ axial length/corneal radius, $S R$ spherical refractive error

$23.63 \pm 1.11 \mathrm{~mm}$ in girls and $24.12 \pm 1.14 \mathrm{~mm}$ in boys; mean CR was $7.75 \pm 0.25 \mathrm{~mm}$ in girls and $7.87 \pm 0.25 \mathrm{~mm}$ in boys; mean AL/CR ratio was $3.05 \pm 0.13 \mathrm{~mm}$ in girls and $3.07 \pm$ $0.13 \mathrm{~mm}$ in boys; and mean SR refraction was $-0.93 \pm 1.85 \mathrm{D}$ in girls and $-0.88 \pm 1.83 \mathrm{D}$ in boys.

On average, the females in each age group had significantly shorter AL, steeper CR, and lower AL/CR ratios compared to the males in their respective age groups $(P<0.01$, Table 2 and Table 3). A positive significant correlation between the SR and the CR (Pearson correlation $=0.027$; covariance $=0.01$; $P=0.001)$ was observed, while the correlation between the $\mathrm{SR}$ and the AL (Pearson correlation $=-0.768$; covariance $=$ - 1.63; $P<0.001)$ and between the SR and the AL/CR ratio (Pearson correlation $=-0.872 ;$ covariance $=-0.21$; $P<0.001)$ was negative.

\section{Growth percentile curves and validation of the curves}

The left part of Fig. 1 shows the growth percentile charts for AL, depending on the age and both genders. From 6 to 15 years of age, all of the percentiles showed a growth trend, except for the percentiles below the first quartile, which appear to stabilize after the age of 12. At this age and for this percentile, no statistical significant growth was observed ($0.10 ; 95 \% \mathrm{CI},-0.36$ to $0.16 ; P=0.23$ for girls and -0.16 ; $95 \% \mathrm{CI},-0.70$ to $0.39 ; P=0.34$ for boys). Specifically in the age group from 6 to 9 years, the AL variable of the lowest percentiles (2nd, 5th, and 10th) showed an increase in elongation that was greater than $0.89 \mathrm{~mm}$ for girls and $0.77 \mathrm{~mm}$ for boys. This behavior clearly attenuated with age and was less than $0.22 \mathrm{~mm}$ in girls and $0.32 \mathrm{~mm}$ in boys at the age of 12 years and onwards.
From 6 to 15 years of age, the 50th percentile of the variable axial length increased by $1.83 \mathrm{~mm}$ for the girls $(22.54 \mathrm{~mm}$ at 6 years of age and $24.37 \mathrm{~mm}$ at 15 years of age), while the 95 th percentile increased by $2.92 \mathrm{~mm}$ in the same group $(23.85 \mathrm{~mm}$ at 6 years of age and $26.77 \mathrm{~mm}$ at 15 years of age). In the boys group, the median increased by $2.02 \mathrm{~mm}(22.99 \mathrm{~mm}$ at 6 years of age and $25.01 \mathrm{~mm}$ at 15 years of age) and the 95 th percentile increased by $2.81 \mathrm{~mm}(24.47 \mathrm{~mm}$ at 6 years of age and $27.28 \mathrm{~mm}$ at 15 years of age).

The right part of the Fig. 1 expresses the myopia prevalence depending on the AL growth percentile curves, taking into account age and gender. For the two groups, the percentiles above the median for the AL showed values that exceed $50.00 \%$ of myopia prevalence. In the case of 90th, 95th, and 98th percentiles, this $50.00 \%$ was exceeded before the age of 9 , reaching values greater than $75.00 \%$ from the age of 12 years and greater than $85.00 \%$ at the age of 15 , as can be observed in 98th percentile ( $85.45 \%$ in girls and $90.55 \%$ in boys). The 75 th percentile achieved values above $50.00 \%$ of myopia prevalence over 9 years of age, $>60.00 \%$ from age 12 , which remains relatively stable until age 15 . The median and the percentiles below it presented values that were below $25.00 \%$ of myopia prevalence at 9 years of age and reached percentages below $45.00 \%$ (40.00\% in girls and $44.09 \%$ in boys) in adolescent stages, at 15 years of age.

To verify the efficacy of identifying the refractive error of the children using the AL growth percentile curves, data from the 226 children with three measurements of the AL and other parameters were used. The baseline AL (at the first visit) was located on the AL growth percentile curves (Fig. 2) and the 


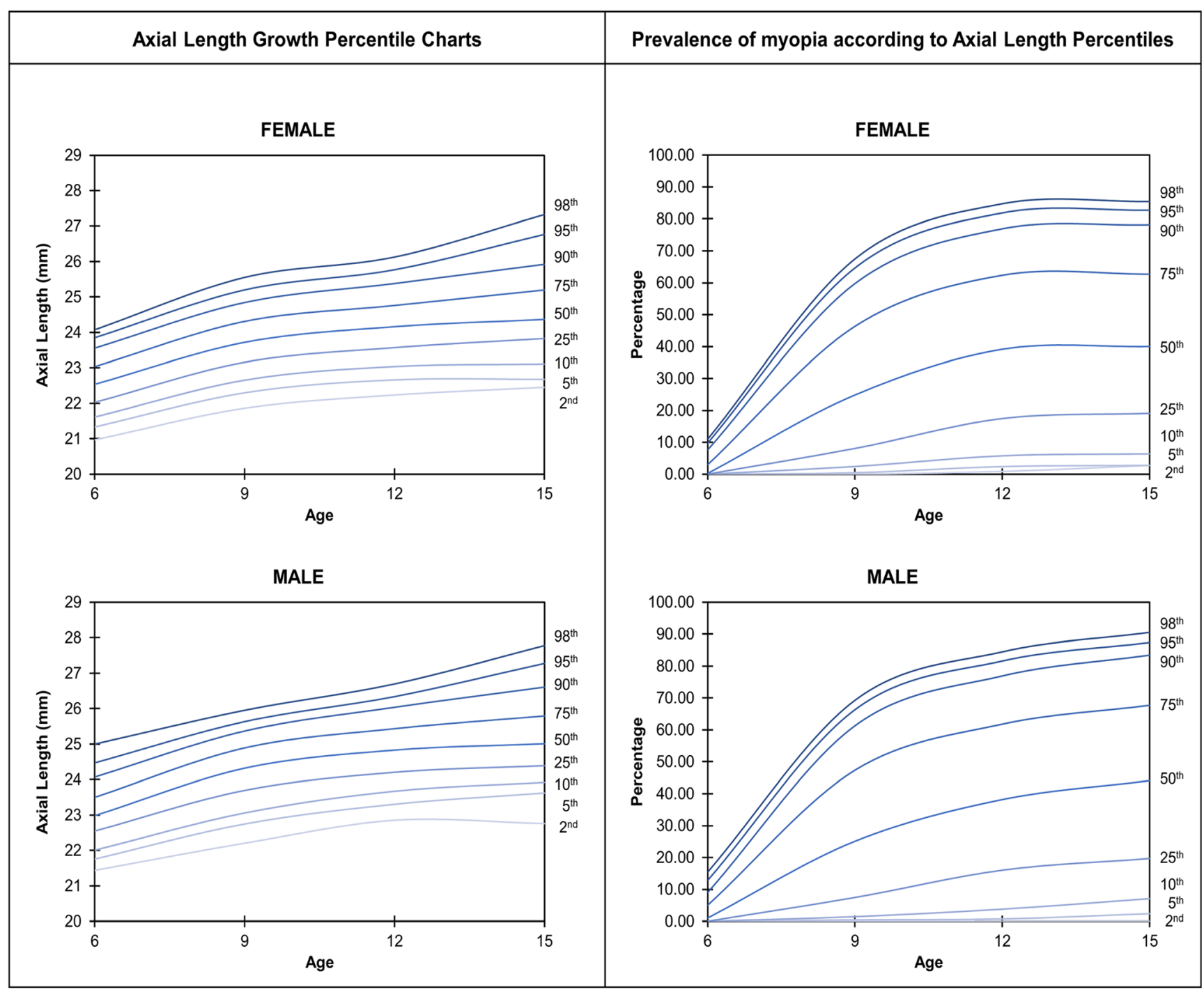

Fig. 1 Left: growth charts (axial length vs age). Right: myopia prevalence as a function of the axial length percentiles. Female (up). Male (down)

children were divided into hyperopes, emmetropes, myopes, and high myopes based on their SR at the third visit. In the female group, those children aged 9 years or older who developed high myopia in the last visit tended to be above the first quartile during their first visit. For this group, the ROC analysis for the cut-off value above the 25th percentile revealed an area under the curve greater than 0.85 (area: 0.876, standard error: $0.043 ; 95 \% \mathrm{CI}, 0.791$ to $0.962 ; P=0.001$ ), with a related sensitivity and specificity of $100.00 \%$ and $87.10 \%$, respectively. For the group of male school children, high myopia developed in the majority of those children whose $\mathrm{AL}$ on the first visit was near to or above the 25th percentile. Again, the ROC analysis revealed an area under the curve greater than 0.75 (area: 0.781 , standard error: $0.067 ; 95 \% \mathrm{CI}, 0.650$ to $0.913 ; P<0.001$ ), with a sensitivity and specificity of $89.50 \%$ and $86.10 \%$, respectively. Different results could be observed, in case younger children are analyzed (age range 69 years). In this age range, the prevalence of myopia begins to have a more pronounced growth, as for example seen in the group of females. For them, the ROC analysis regarding the cut-off value above the 50th percentile revealed an area under the curve greater than 0.85 (area: 0.875, standard error: 0.053; 95\% CI, 0.771 to $0.979 ; P=0.013$ ), with a related sensitivity and specificity of $100.00 \%$ and $71.90 \%$, respectively. For the male group of the same age range, high myopia developed in the majority of those children where AL on the first visit was above the 50th percentile. Again, the ROC analysis revealed an area under the curve greater than 0.80 (area: 0.835, standard error: $0.080 ; 95 \% \mathrm{CI}, 0.679$ to $0.991 ; P<0.001$ ), with a sensitivity and specificity of $90.90 \%$ and $60.80 \%$, respectively.

\section{Comparison to European data}

The percentile growth curves of the AL were compared with the growth curves of the European children's population 

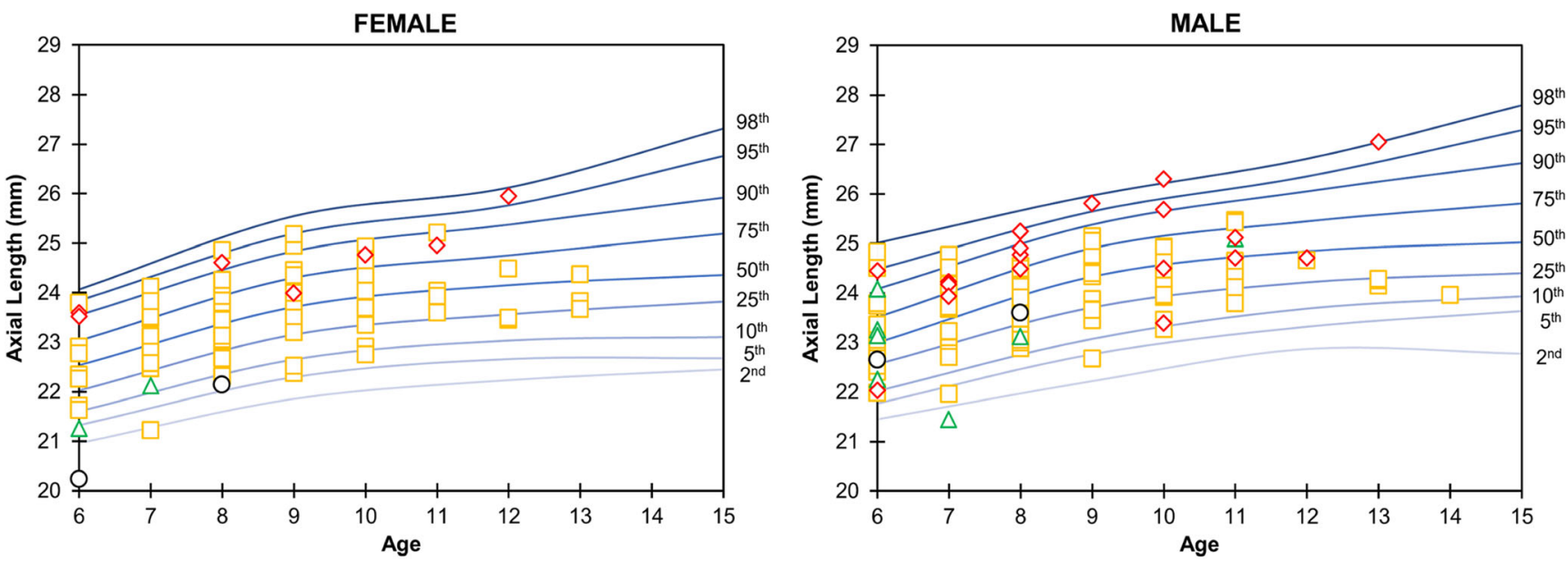

$\bigcirc$ Hyperopia $\triangle$ Emmetropia $\square$ Myopia $\diamond$ High Myopia

Fig. 2 Distribution of age-specific axial length at first visit and classification depending on the spherical refractive error at third visit. The baseline axial length at the first visit was located on the axial length growth percentile curves in conjunction with their spherical refraction after the

published by Tideman et al. [22]. As shown in Table 4, similar values were observed in the percentiles of both children cohorts for the AL at the age of 6 years, while there was a greater difference between these two populations in the percentiles of both children cohorts at the ages of 9 and 15 years, clearly indicating higher percentile values for the Chinese group for these two variables. As observed in the European children's cohort [22], the 50th percentile of the AL variable was $22.06 \mathrm{~mm}$ for girls and $22.59 \mathrm{~mm}$ for boys at the age of 6 , while similar results were found in our study population, $22.54 \mathrm{~mm}$ and $22.99 \mathrm{~mm}$ for females and males, respectively. At the age of 9 and 15, the differences became more noticeable. At 9 years of age, the 50th percentile showed values of $22.79 \mathrm{~mm}$ for girls and $23.31 \mathrm{~mm}$ for boys in the European population, while in the Chinese population, the values were

Table 4 Percentiles of AL in 6-, 9-, and 15-year-old European and Chinese children of both genders. European children's population comes from Tideman et al. [22]

\begin{tabular}{|c|c|c|c|c|c|}
\hline & \multirow[t]{2}{*}{ Percentile } & \multicolumn{2}{|l|}{ Female } & \multicolumn{2}{|l|}{ Male } \\
\hline & & European & Chinese & European & Chinese \\
\hline \multirow[t]{3}{*}{6 years } & 25 & 21.66 & 22.03 & 22.14 & 22.55 \\
\hline & 50 & 22.06 & 22.54 & 22.59 & 22.99 \\
\hline & 75 & 22.49 & 23.04 & 23.01 & 23.50 \\
\hline \multirow[t]{3}{*}{9 years } & 25 & 22.33 & 23.16 & 22.83 & 23.70 \\
\hline & 50 & 22.79 & 23.72 & 23.31 & 24.32 \\
\hline & 75 & 23.25 & 24.31 & 23.79 & 24.89 \\
\hline \multirow[t]{3}{*}{15 years } & 25 & 22.68 & 23.83 & 23.17 & 24.39 \\
\hline & 50 & 23.15 & 24.37 & 23.65 & 25.01 \\
\hline & 75 & 23.65 & 25.20 & 24.21 & 25.80 \\
\hline
\end{tabular}

third visit (symbols; black circle: hyperopes, green triangle: emmetropes, yellow square: myopes and red rhomb: high myopes). Female (left). Male (right)

$23.72 \mathrm{~mm}$ for girls and $24.32 \mathrm{~mm}$ for boys. At age 15, the European population showed values of the 50th percentile equal to $23.15 \mathrm{~mm}$ in the female group and $23.65 \mathrm{~mm}$ in the male group, while on the other hand in the our study population, the values were $24.37 \mathrm{~mm}$ in the female group and $25.01 \mathrm{~mm}$ in the male group.

\section{Discussion}

\section{Prevalence of refractive errors}

This paper showed what has been commented on the epidemic levels of myopia reached in areas of the Asian continent [24, 25]. The results showed prevalence's of myopia above $12.00 \%$ at the age of 6 years, with a continuous progression from the age of 7 years, reaching prevalence levels close to $55.00 \%$ in both genders. These levels continue to grow visibly until reaching approximately $90.00 \%$ at teen years of age.

Several studies have described the refractive error and ocular components of different groups of school-aged children depending on age, gender, or ethnicity [26, 27]. Asian ethnicity has been reported as the one with the greatest effect of age associated with a greater myopic spherical equivalent refractive error compared to other ethnic groups [26, 28]. As expected, the current study showed that a greater tendency of myopia with age was accompanied by the values of each of the variables analyzed in the Table 2 and Table 3 .

In terms of gender and age dependency, our findings were similar to those reported in other cohort studies $[19,22,26$, 28-32]. AL levels were lower in the female group compared to the male group. Although in both genders the CR remained 
stable with increasing age, flattest corneas were found in the male group. With regard to the AL/CR ratio, the findings were similar to those found in axial length with lower amounts of ratio in the female group.

Fledelius et al. (2014) reported higher AL in the male group with mean values of $23.55 \mathrm{~mm}$ compared to $22.90 \mathrm{~mm}$ in females ( $0.65 \mathrm{~mm}$ mean difference), which began to be noticeable from 7 years of age, with a mean difference of $0.89 \mathrm{~mm}$. These differences were attenuated with the increase in age, until the age of 20.

Comparable results were described by Twelker et al. [26]. They reported higher axial length values in the male group with a mean difference in axial length of $0.4 \mathrm{~mm}$, which was reported as ethnically dependent and similar results were reported by Ip et al. [28]. Moreover, both observed a stable behavior of corneal radius across age groups, reporting steepest corneas in the female group. He et al. [19] reported statistical significant differences between boys and girls for the $\mathrm{AL}$, the $\mathrm{AL} / \mathrm{CR}$ ratio, and the spherical equivalent refractive error, while all of these variables were reported to be higher in boys. In opposition to He et al. [19], no differences in spherical refractive error were associated with gender and the steepest corneal radius in the current study, for the female group. Regarding the AL/CR ratio, He et al. [19] observed a mean value of 2.90 in school children at the age of 6 years, with a gradual increase to 3.03 at the age of 12 . Similar values can be found in the current study in the case of the 6-year-old group, since for the 12-year-old group, values higher than 3.10 were reported.

Due to the high correlation that was observed between the $\mathrm{AL} / \mathrm{CR}$ ratio and the spherical equivalent refractive error [33], many studies have proposed the determination of optimal cutoff values in AL/CR ratio for myopia detection tasks [19, 34]. Both Grosvenor and Goss [34] and He et al. [19] found very similar cutting values, $>2.99$ and 3.00, respectively. The current study found similar cutoff points for the AL/CR ratio at the ages of 7 to 8 years, which was the age when myopia became the refractive state with the highest prevalence (Table 2 and Table 3).

\section{Growth percentile curves}

One of the latest methods used to estimate the risk of myopia development has been the use of growth percentile curves of different variables such as refraction, AL, CR, and AL/CR ratio [21, 22]. Chen et al. [21] developed percentile curves of refraction based on data of 4218 children (age range: 515 years) collected from the "Guangzhou refractive error study". They reported that children at young age with percentile refractive curves located below lower percentiles were more likely to have high myopia at 15 years or adulthood. Using axial length to develop growth curves (Fig. 2), it can be observed that for both genders, the age of 9 years is most important, since the probabilities of reaching high levels of myopia increases, when axial length values were located above the 50th percentile at this age. Furthermore, Tideman et al. [22] generated a growth charts for AL, CR, and AL/CR ratio based on large epidemiological cohorts of European children and adults. On average, comparing with our growth percentile curves in Chinese children, European children, in both genders, showed lower percentile values, in $\mathrm{AL}$ and $\mathrm{AL} / \mathrm{CR}$ ratio, from the age of 9 years. These differences are governed by all those environmental, genetic, and/or epigenetic factors that play a fundamental role in the refractive development of the human eye [9-11, 27].

\section{Limitation of the study}

Despite the importance of the results obtained, certain points must be taken into account. Nonhomogeneity of the sample size at each age of both genders may be one of the reasons why the prevalence levels of refractive states have abrupt changes from age 7 onwards. Moreover, given the importance of ethnicity in the development of the refractive state of the visual system, it is of great importance to make reference curves with populations of the same race. For this reason, the curves developed with the presented data may not be valid for children of other ethnicities. The results of the current study have to be taken with caution, when one is trying to translate the current findings to children of other ethnicities, age groups, or with different prevalence's of myopia. It is quite clear that the development of such percentile curves pretty much depends on the quality and amount of data that is used for the development. Therefore, these curves will change for example in case the onset of myopia is shifted or the total prevalence of refractive errors is different. Nevertheless, these curves allow us to obtain standards to be able to individually monitor a specific subject and assess whether its axial length growth pattern is within or outside the limits of normal eye length variation and moreover, to have reference curves that allow us to compare with the rest of the ethnic groups and populations.

\section{Conclusions}

The presented axial length percentile curves provide a simple method for estimating the probability of myopia in Chinese children's populations, based on age, gender, and eye variables. This method can be the starting point for approaching and applying preventive treatments against the development of myopia at an early age with the aim to reduce the risk of developing high amounts of myopic refractive errors. 
Acknowledgments European Union's Horizon 2020 research and innovation programme under the Marie Skłodowska-Curie grant agreement (grant number 675137).

Funding This study was funded by European Union's Horizon 2020 research and innovation programme under the Marie Skłodowska-Curie grant agreement (grant number 675137).

\section{Compliance with ethical standards}

The study was approved by the Ethical Committee of the Wuhan Center for Adolescent Poor Vision Prevention \& Control. After explaining in detail all study procedures and before starting the study, all parents were carefully informed about study's risks and benefits, and signed an informed consent in accordance with the Declaration of Helsinki (1964).

Conflict of interest The authors declare that they have no conflict of interest.

\section{Research involving human participants}

Ethical approval All procedures performed in studies involving human participants were in accordance with the ethical standards of the institutional and/or national research committee and with the 1964 Helsinki declaration and its later amendments or comparable ethical standards.

Informed consent Informed consent was obtained from all individual participants included in the study.

Open Access This article is distributed under the terms of the Creative Commons Attribution 4.0 International License (http:// creativecommons.org/licenses/by/4.0/), which permits unrestricted use, distribution, and reproduction in any medium, provided you give appropriate credit to the original author(s) and the source, provide a link to the Creative Commons license, and indicate if changes were made.

\section{References}

1. Atkinson J, Braddick O, Nardini M, Anker S (2007) Infant hyperopia: detection, distribution, changes and correlates-outcomes from the Cambridge infant screening programs. Optom Vis Sci 84(2):8496. https://doi.org/10.1097/OPX.0b013e318031b69a

2. Fledelius HC, Christensen AC (1996) Reappraisal of the human ocular growth curve in fetal life, infancy, and early childhood. $\mathrm{Br}$ J Ophthalmol 80(10):918-921

3. Gordon RA, Donzis PB (1985) Refractive development of the human eye. Arch Ophthalmol 103(6):785-789

4. Flitcroft DI (2014) Emmetropisation and the aetiology of refractive errors. Eye (Lond) 28(2):169-179. https://doi.org/10.1038/eye. 2013.276

5. Ikuno Y (2017) Overview of the complications of high myopia. Retina 37(12):2347-2351. https://doi.org/10.1097/IAE. 0000000000001489

6. Wallman J, Winawer J (2004) Homeostasis of eye growth and the question of myopia. Neuron 43(4):447-468. https://doi.org/10. 1016/j.neuron.2004.08.008

7. Zadnik K, Mutti DO, Friedman NE, Qualley PA, Jones LA, Qui P, Kim HS, Hsu JC, Moeschberger ML (1999) Ocular predictors of the onset of juvenile myopia. Invest Ophthalmol Vis Sci 40(9): 1936-1943
8. Zadnik K, Satariano WA, Mutti DO, Sholtz RI, Adams AJ (1994) The effect of parental history of myopia on children's eye size. JAMA 271(17):1323-1327

9. Pan CW, Ramamurthy D, Saw SM (2012) Worldwide prevalence and risk factors for myopia. Ophthalmic Physiol Opt 32(1):3-16. https://doi.org/10.1111/j.1475-1313.2011.00884.x

10. Kim EC, Morgan IG, Kakizaki H, Kang S, Jee D (2013) Prevalence and risk factors for refractive errors: Korean National Health and nutrition examination survey 2008-2011. PLoS One 8(11):e80361. https://doi.org/10.1371/journal.pone.0080361

11. Stambolian D (2013) Genetic susceptibility and mechanisms for refractive error. Clin Genet 84(2):102-108. https://doi.org/10. $1111 /$ cge. 12180

12. O'Connor AR, Stephenson TJ, Johnson A, Tobin MJ, Ratib S, Fielder AR (2006) Change of refractive state and eye size in children of birth weight less than $1701 \mathrm{~g}$. Br J Ophthalmol 90(4):456460. https://doi.org/10.1136/bjo.2005.083535

13. Holmstrom GE, Larsson EK (2005) Development of spherical equivalent refraction in prematurely born children during the first 10 years of life: a population-based study. Arch Ophthalmol 123(10):1404-1411. https://doi.org/10.1001/archopht.123.10.1404

14. Larsson EK, Holmstrom GE (2006) Development of astigmatism and anisometropia in preterm children during the first 10 years of life: a population-based study. Arch Ophthalmol 124(11):16081614. https://doi.org/10.1001/archopht.124.11.1608

15. Mutti DO, Zadnik K (1995) The utility of three predictors of childhood myopia: a Bayesian analysis. Vis Res 35(9):1345-1352

16. Zadnik K, Sinnott LT, Cotter SA, Jones-Jordan LA, Kleinstein RN, Manny RE, Twelker JD, Mutti DO, Collaborative Longitudinal Evaluation of E, Refractive Error Study G (2015) Prediction of juvenile-onset myopia. JAMA Ophthalmol 133(6):683-689. https://doi.org/10.1001/jamaophthalmol.2015.0471

17. Medina A (2015) The progression of corrected myopia. Graefes Arch Clin Exp Ophthalmol 253(8):1273-1277. https://doi.org/10. 1007/s00417-015-2991-5

18. Medina A, Greene PR (2015) Progressive myopia and lid suture myopia are explained by the same feedback process: a mathematical model of myopia. J Nat Sci 1(6)

19. He X, Zou H, Lu L, Zhao R, Zhao H, Li Q, Zhu J (2015) Axial length/corneal radius ratio: association with refractive state and role on myopia detection combined with visual acuity in Chinese schoolchildren. PLoS One 10(2):e0111766. https://doi.org/10. 1371/journal.pone. 0111766

20. Mushtaq MU, Gull S, Mushtaq K, Abdullah HM, Khurshid U, Shahid U, Shad MA, Akram J (2012) Height, weight and BMI percentiles and nutritional status relative to the international growth references among Pakistani school-aged children. BMC Pediatr 12: 31. https://doi.org/10.1186/1471-2431-12-31

21. Chen Y, Zhang J, Morgan IG, He M (2016) Identifying children at risk of high myopia using population centile curves of refraction. PLoS One 11(12):e0167642. https://doi.org/10.1371/journal.pone. 0167642

22. Tideman JWL, Polling JR, Vingerling JR, Jaddoe VWV, Williams C, Guggenheim JA, Klaver CCW (2017) Axial length growth and the risk of developing myopia in European children. Acta Ophthalmol. https://doi.org/10.1111/aos.13603

23. Chen W, McAlinden C, Pesudovs K, Wang Q, Lu F, Feng Y, Chen J, Huang J (2012) Scheimpflug-Placido topographer and optical low-coherence reflectometry biometer: repeatability and agreement. J Cataract Refract Surg 38(9):1626-1632. https://doi.org/10. 1016/j.jcrs.2012.04.031

24. Dolgin E (2015) The myopia boom. Nature 519(7543):276-278. https://doi.org/10.1038/519276a

25. Wang SK, Guo Y, Liao C, Chen Y, Su G, Zhang G, Zhang L, He M (2018) Incidence of and factors associated with myopia and high myopia in Chinese children, based on refraction without 
Cycloplegia. JAMA Ophthalmol 136(9):1017-1024. https://doi. org/10.1001/jamaophthalmol.2018.2658

26. Twelker JD, Mitchell GL, Messer DH, Bhakta R, Jones LA, Mutti DO, Cotter SA, Klenstein RN, Manny RE, Zadnik K, Group CS (2009) Children's ocular components and age, gender, and ethnicity. Optom Vis Sci 86(8):918-935

27. Morgan IG, Ohno-Matsui K, Saw SM (2012) Myopia. Lancet 379(9827):1739-1748. https://doi.org/10.1016/S0140-6736(12) 60272-4

28. Ip JM, Huynh SC, Robaei D, Kifley A, Rose KA, Morgan IG, Wang JJ, Mitchell P (2008) Ethnic differences in refraction and ocular biometry in a population-based sample of 11-15-year-old Australian children. Eye (Lond) 22(5):649-656. https://doi.org/10. 1038/sj.eye.6702701

29. Zadnik K, Mutti DO, Friedman NE, Adams AJ (1993) Initial crosssectional results from the Orinda longitudinal study of myopia. Optom Vis Sci 70(9):750-758

30. Ojaimi E, Rose KA, Morgan IG, Smith W, Martin FJ, Kifley A, Robaei D, Mitchell P (2005) Distribution of ocular biometric parameters and refraction in a population-based study of Australian children. Invest Ophthalmol Vis Sci 46(8):2748-2754. https://doi. org/10.1167/iovs.04-1324
31. Selovic A, Juresa V, Ivankovic D, Malcic D, Selovic Bobonj G (2005) Relationship between axial length of the emmetropic eye and the age, body height, and body weight of schoolchildren. Am J Hum Biol 17(2):173-177. https://doi.org/10.1002/ajhb.20107

32. Ip JM, Huynh SC, Kifley A, Rose KA, Morgan IG, Varma R, Mitchell P (2007) Variation of the contribution from axial length and other oculometric parameters to refraction by age and ethnicity. Invest Ophthalmol Vis Sci 48(10):4846-4853. https://doi.org/10. 1167/iovs.07-0101

33. Grosvenor T (1988) High axial length/corneal radius ratio as a risk factor in the development of myopia. Am J Optom Physiol Optic 65(9):689-696

34. Grosvenor T, Goss DA (1998) Role of the cornea in emmetropia and myopia. Optom Vis Sci 75(2):132-145

Publisher's note Springer Nature remains neutral with regard to jurisdictional claims in published maps and institutional affiliations. 